\title{
El concubinato. Propuesta de nuevos derechos
}

\section{Concubinage. A proposal for new rights}

\author{
Juan Miguel Ramos Lorenzo*
}

Facultad de Derecho, Universidad de San Martín de Porres, Perú

\section{Resumen}

Lo que en tiempos pasados la legislación y la doctrina han llamado concubinato -inclusive por el origen etimológico de la palabra-, la ley peruana, dejando de lado la legislación generalizada y la doctrina, lo denomina unión de hecho, que puede confundirse con las diversas clases de uniones, no de derecho, sino para distintos fines, como el comercial; tampoco al de cohabitar o hacer vida en común entre un hombre y una mujer, como si fueran casados. Por ello, en el presente trabajo se propone el reconocimiento legal de otros derechos inherentes a los concubinos; que el ordenamiento legal continúa silenciando, absteniéndose de establecerlos, como lo exige una verdadera normación jurídica y que, en su defecto, el poder jurisdiccional de los tribunales debería declarar y no ampararse en el argumento de que es una institución «sombra del matrimonio».

Palabras clave: concubinato, derecho, ley peruana, constitución peruana, código civil. 


\begin{abstract}
What formerly was called concubinage (based on the etymological origin of the word) according to legislation and doctrine is now known as commonlaw marriage by Peruvian law, disregarding general legislation and doctrine. This term can be confused with different types of unions, not marriage or that of the living together between a man and woman as if they were married, but rather that for different purposes, such as commercial interests. Therefore, this work proposes the legal recognition of other rights inherent to common-law spouses that the legal system continues to keep silent, refraining from establishing them, as required by a true legal code, and that the jurisdictional power of courts should declare and not rely on the argument that common-law marriage is an institution considered in the «shadow of marriage.»
\end{abstract}

Keywords: concubinage, rights, peruvian law, peruvian constitution, civil code.

\title{
Origen etimológico de concubinato
}

Existen varias versiones sobre la procedencia de este vocablo, siendo las más difundidas las siguientes:

- Proviene de las voces latinas con y cubito, que se traducen en «acostarse con», «acostarse juntos» o «dormir juntos», que aluden a la comunidad de hecho o relación sexual (Sopena, 1963, p. 2161).

- Deriva del latín concubinatus del verbo comcubere, o concumbere (de cunu y cubere $=$ yacer juntos), referido a comunicación o trato de un hombre y una mujer.

- También, se dice que deriva de concubena, que igualmente alude a «dormir juntos» o «acostarse». 


\section{Definición de concubinato}

Se le ha definido dándole diversas acepciones, como:

- La unión de hecho de varón y mujer que sin estar casados hacen vida de tales.

- La convivencia estable de una pareja heterosexual conformando una unidad familiar.

- En el art. 5 de la Constitución se dice: «Unión estable de un varón y una mujer, libres de impedimento matrimonial, que forman un hogar de hecho» (Constitución Política del Perú de 1993, 2008).

- Por su parte en el art. 326 del Código Civil se le llama, con más amplitud, «la unión de hecho, voluntariamente realizada y mantenida por un varón y una mujer, libres de impedimento matrimonial, para alcanzar finalidades y cumplir deberes semejantes a los del matrimonio» (Código Civil, 2017).

\section{Clases de concubinato}

La doctrina, e inclusive la ley, ofrecen la siguiente clasificación:

- Concubinato propio, estricto sensu o en sentido estricto. Aquel que, por cumplir con los requisitos exigidos para tal, tiene reconocimiento legal y produce los efectos jurídicos que se le atribuyen.

- Concubinato lato, impropio, o irregular. El que carece de alguno de los requisitos para ser reconocido como forma regular de convivencia pero que, sin embargo, se le reconoce algún efecto, como el derecho a una pensión alimenticia o a un resarcimiento por enriquecimiento indebido o abandono de uno de sus miembros en perjuicio del otro. 


\section{Requisitos del concubinato propio}

Siguiendo el texto descriptivo del art. 326 del Código Civil (2017) encontramos como exigencias:

1. Voluntariedad. Debe constituirse por una unión voluntaria y no forzada, porque esta lindaría con el secuestro y lo viciaría como acto. Y, también debe existir lo que en el matrimonio constituye la affectio maritalis, o voluntad de hacer vida en común.

2. Heterosexualidad. Es decir, deben formarlo personas de diferente sexo, desechándose así los ayuntamientos homosexuales. Esto es que debe tratarse de un varón y una mujer.

Debe tenerse presente que en nuestro Código Civil la homosexualidad es una causal de anulabilidad del matrimonio (art. 277, inc. 5), cuando es anterior a este, y de divorcio, cuando es posterior (art. 33. inc. 9).

Sin embargo, en algunas legislaciones como en Argentina, en Ecuador, en algunos estados de Estados Unidos de Norteamérica, entre otras, se permite en parejas homosexuales.

3. Ausencia de impedimento matrimonial. La pareja no debe tener impedimento matrimonial de ninguna clase, absoluto o relativo, sea por edad, salud, matrimonio, parentesco, condena, con la extensión que enumeran los arts. 241, 242 y 243 del Código Civil.

En consecuencia, no podrán formar concubinato los menores de 16 años, los que sufran las enfermedades precisadas por la ley, los parientes consanguíneos, afines y por adopción dentro de los grados preestablecidos, etc.

4. Permanencia o estabilidad. Nuestro Código Civil exige para su constitución una permanecía mínima de dos años continuos (otras legislaciones demandan tres, cuatro y cinco años). Es decir, que deben ser ininterrumpidos y no fraccionados, por lo que este requisito podría ser burlado, maliciosamente, con sucesivos alejamientos para evitar su consumación. 
La permanencia exigida pone en evidencia una voluntad de vida en común continua y no esporádica o circunstancial.

Con ello además, se descartan las uniones pasajeras o fugaces de simples amantes o lo que hoy denominan «novios».

5. Publicidad. No debe ser una unión oculta o clandestina, sino que en ella debe darse o existir una posesión constante de estado concubinario. Es decir, debe ser notoria la apariencia de matrimonio o comunidad de vida, en la que públicamente se cumplen los deberes de comunidad de vida, que para los casados menciona el mismo Código Civil.

6. Singularidad. Debe existir fidelidad y exclusividad recíproca entre los integrantes de la pareja, no admitiéndose uniones paralelas, simultáneas o plurales, de modo que, no es posible que uno de ellos o ambos, mantengan relaciones sexuales a la vez con otros u otras, lo que lindaría con la promiscuidad. El requisito de la monogamia en el matrimonio es exigido también en estas uniones.

\section{Antecedentes históricos}

El concubinato es tan antiguo como la humanidad, toda vez que originariamente no existió el matrimonio como institución, el mismo que fue producto posterior de costumbres y leyes que lo establecieron.

Se tiene noticia de este en culturas, regímenes o codificaciones de todos los tiempos, como los que se describen brevemente a continuación:

\section{Código de Hammurabi}

Constituye el texto legal más antiguo conocido, dado por el rey Hammurabi, en la cuidad de Babilonia, la que después se constituye en un imperio desarrollado en la Baja Mesopotamia, ubicando su origen alrededor del año 1750 a. C. Fue descubierto por arqueólogos franceses en 1902 en Susa, Persia, sobre una losa del basalto, escrito en lengua acadia. Tiene como medidas casi 2.4 metros de alto, con 3600 líneas y actualmente se guarda en el Museo del Louvre. 
Entre otros principios allí se establece la ley del Talión: ojo por ojo, diente por diente, es decir, «si un hombre destruye el ojo a otro hombre, se le destruirá el ojo» (Peinado, 1993).

En el Código de Hammurabi se admite como institución legal el concubinato y se regula la situación de la familia, priorizándose lo concerniente al matrimonio y la herencia.

De acuerdo a los historiadores, los babilónicos conocieron el divorcio, generalmente a instancia del varón cuando la mujer era estéril. La mujer podía solicitarlo con fundamento suficiente, ya que si no lo demostraba, se le ataba y arrojaba al río. En cambio, si lo demostraba, se autorizaba su separación y la recuperación de su dote. Se refiere que una de las concubinas más famosas del rey persa Artajerjes fue Comartidene.

\section{En Egipto}

En el antiguo Egipto no existía ley que prohibiese el concubinato. Además, un hombre de clase alta podía casarse con cuanta mujer quisiera, pero normalmente las segundas solían ser concubinas, sirvientas o esclavas.

En numerosas tumbas se hallaron mujeres acompañadas de sus hijos que se supone también eran hijos del sepultado, pero que en este caso no era la esposa.

\section{En la cultura hindú}

Las Leyes de Manu en la India Antigua, establecía lo que estaba permitido y lo que estaba prohibido, siguiendo normas en lo moral y en lo social.

Se establecía que la mujer debía ser fiel y reservarse solo para su marido. Le estaba prohibido hablar, e inclusive ver a otro hombre cuando no estaba acompañada de su esposo; tampoco debía ser vista por otros hombres sin su marido.

Mientras que el varón podía casarse varias veces, la mujer no tenía el mismo derecho. Solamente una sola vez se podía dar a una mujer en 
matrimonio. El padre que ofrecía a su hija en segundas nupcias era condenado. La mujer que dejaba a su marido para irse con otro era despreciada al igual que sus hijos y su nuevo esposo. Toda su vida estaba sometida a los varones, no gozaba de libertad fuera del hogar. Sin embargo, la dependencia debe ser siempre respetuosa, destacando a la mujer virtuosa.

\section{En Roma}

«Concubinato era en Derecho romano la unión estable entre un hombre y una mujer sin affectio maritalis. Esta característica tiene como consecuencia que no se confunda con la situación de matrimonio» (Fernandez de León, 1962).

El concubinato, conocido como More Uxorio fue normado por el ius gentium, llegando a su mayor difusión al final de la República. Las leyes lo consideraban ilegitimo, pero lo existía en atención a la diferencia de las personas.

Cuando ambos concubinos eran esclavos la unión era llamada contubernio.

En Roma el concubinato existió por cuanto la ley no permitía el matrimonio de personas de diferente clase social, llegando, inclusive, a castigar penalmente las relaciones extramatrimoniales consideradas como adulterium, incestum o stuprum. Con el tiempo, se atemio la severidad de la legislación, tolerando su existencia, llegando a considerarlo como un cuasi matrimonio, con determinadas restricciones, como por ejemplo, que la concubina no quede embarazada, puesto que la procreación estaba reservada para la esposa. En todo caso, los hijos resultantes no podían adquirir la condición de hijos legítimos.

Con la llegada del cristianismo buscaron robustecer el matrimonio y a dificultar las uniones de hecho, facilitando su transformación en uniones matrimoniales y mejorando la condición de los hijos, nombrándolos «naturales». 


\section{En los pueblos bárbaros y germanos}

Los romanos llamaban bárbaros a los pueblos que existían más allá de sus fronteras y quienes al final fueron los autores de su caída. En ellos, el concubinato se dio en las uniones entre libres y siervos, toda vez que no se permitía el matrimonio entre personas de distinto rango social, siendo sustituido, posteriormente, por el matrimonio llamado «de mano izquierda» o morganático, que no concedía a la mujer los beneficios de los títulos ni jerarquía del marido.

El concubinato entre los bárbaros tampoco otorgaba exclusión pudiendo el varón tener más de una concubina, quienes no eran consideradas esclavas o sirvientas. No había diferencia entre hijos legítimos e ilegitimo. Todos tenían derecho a la herencia (Rojas, 2005).

\section{En la Edad Media}

A pesar de las prédicas de la religión católica en contra, el concubinato subsistió con diversas denominaciones, como barraganía, amancebamiento, etc.

Es sabido que los nobles y las clases superiores tenían públicamente más de una concubina, cuyos descendientes eran conocidos como bastardos, todo lo cual trascendió en el tiempo hasta llegar a América con los conquistadores quienes tomaban a las indias para su amancebamiento sin casarse con ellas, ocasionando hijos ilegítimos o mestizos, como el caso del cronista Garcilaso de la Vega, nacido de las relaciones de un capitán español con una princesa indígena.

\section{El código de Napoleón}

Se abstuvo de legislarlo, considerándolo como un acto inmoral e ignorándolo completamente no obstante la innegable difusión alcanzada en ese tiempo.

Siguiendo a este código muchas de las codificaciones americanas también se abstuvieron de regularlo, entre ellos, nuestros códigos civiles de 1852 y 1936. 


\section{El concubinato en el Perú}

\section{En las culturas preincas}

No se encuentran mayores datos sobre ello, salvo que las relaciones familiares estuvieron regidas por normas consuetudinarias (la costumbre), que existía desde entonces, iniciándose con una relación que precedía a una subsiguiente relación conyugal. Se afirma que, desde estos tiempos, se reinventa la práctica conocida como el servinacuy.

\section{En el imperio incaico}

Prevalecía la unión pública y monógama para la gente del pueblo, pero para la nobleza estaba permitida la poligamia. Se podía mantener relaciones convivenciales con diversas mujeres, quienes se agrupaban en casas conocidas como acllahuasi, con gran cantidad de hijos, entre los que alguno pudo llegar a la máxima dignidad inca.

En el tiempo de los incas el servinacuy, tincunacuspa, servisiña, tuvieron características de verdaderas familias, existiendo actualmente con importante discusión en el elemento indígena y campesino.

\section{Las leyes de indias}

Se dieron para las colonias conquistadas prohibiendo el matrimonio de españoles con personas de las tierras conquistadas, dando lugar a la proliferación de los amancebamientos, que no pudieron erradicarse a pesar de las protestas de los evangelizadores, ocurriendo inclusive hasta con los virreyes, como en el caso de Amat y Juniet y la conocida Perricholi, para quien, se afirma, se mandó construir el Paseo de Aguas en la Alameda de los Descalzos del hoy distrito del Rímac.

En la época colonial esta práctica continuó, sin que nada impidiera esta clase de uniones ni siquiera las persecusiones de la santa inquisición. Se dieron disposiciones prohibiéndolo, como es el caso del virrey Toledo quien ordeno desterrarlas, recurriendo incluso a castigos corporales. 


\section{Código Civil de 1852}

Fue nuestro primer código republicano y sancionó en su art. 1925 inc. 2 que el concubinato era causal de separación de los casados, sin reconocerlo como institución que genera derechos y obligaciones, declarando en su artículo 156 que el matrimonio canónico era el único que producía efectos civiles, y por tanto, solo podían celebrarlo los católicos siguiendo las disposiciones acordadas y establecidas en el Concilio de Trento; dejando al margen a los no católicos cuyas uniones no eran consideradas matrimonio (Código Civil, 1852).

\section{Código Civil de 1936}

Nuestro segundo código republicano tampoco lo legisló, dejándose para el posible enriquecimiento del conviviente, a costa del abandono de su pareja, aplicándose por analogía la disposición genérica de su art. 1149 de que «aquel que se enriquece indebidamente a expensas de otro, está obligado a indemnizarlo», así como también su artículo 1732 sobre sociedad de hecho pero sin ocuparse en forma alguna de los efectos que emanaban de las uniones de hecho, salvo en el art. 366 inc. 4 para los casos en que podía establecerse la paternidad ilegitima cuando el supuesto progenitor hubiera vivido en concubinato con la madre en época coetánea con la concepción, sin precisarse los requisitos para considerar que hubo concubinato, a tal extremo que mediante ejecutoria suprema de 7 de enero de 1939 se estableció que:

No obstante que el testador declara que determinados bienes pertenecen a su concubina por haberle proporcionado ella el dinero para adquirirlos, y que otro bien había sido adquirido únicamente por la concubina, nada le pertenece a esta y debe ser considerado masa hereditaria. (Código Civil de 1936, 1971) 


\section{El concubinato en las Constituciones de 1979, 1993 y en el actual Código Civil}

\section{La Constitución en 1979}

Recién en esta ley fundamental se reconoció el concubinato concediéndole jerarquía constitucional al declarar en su art. 9 que:

La unión estable de un varón y una mujer, libres de impedimento matrimonial, que forman un hogar de hecho por el tiempo y las condiciones que señala la ley da lugar a una sociedad de bienes que se sujeta al régimen de la sociedad de gananciales en cuanto es aplicable. (Constitución Política del Perú de 1979, 1979)

Se establecieron entonces como sus requisitos que sea una unión estable; que se trate de un hombre y una mujer, y que estén libres de impedimento matrimonial; dejando a lege ferenda determinar su tiempo de duración y las demás condiciones para ser considerado como tal.

Sin embargo, fue un evidente avance a pesar de que ya otras constituciones como las de Cuba desde 1940, Bolivia desde 1945, Panamá desde 1964, así como los códigos civiles de México, Distrito Federal, desde el 30 de agosto de 1928 y Venezuela desde el 1 de octubre de 1942 ya lo habían reconocido.

\section{La Constitución de 1993}

Tiene establecido en su artículo 5 lo siguiente: «La unión estable de un varón y una mujer, libres de impedimento matrimonial que forman un hogar de hecho, da lugar a una comunidad de bienes sujeta al régimen de la sociedad de gananciales en cuanto sea aplicable» (Constitución Política del Perú de 1979, 1979). 


\section{El Código Civil actual}

El código actual vigente desde el 14 de noviembre de 1984, desarrollando el artículo 5 de la constitución de 1993, estableció originariamente en su artículo 326 lo que se detalla a continuación:

La unión de hecho, voluntariamente realizada y mantenida por un varón y una mujer, libre de impedimento matrimonial, para alcanzar finalidades y cumplir deberes semejantes a los del matrimonio, origina una sociedad de bienes que se sujeta al régimen de sociedades gananciales, en cuanto le fuera aplicable, siempre que dicha unión haya durado por lo menos 2 años continuos. (Constitución Política del Perú de 1979, 1979)

Surge de manera paralela con respecto a la institución del matrimonio donde el concubinato es libre y se inicia a voluntad de la pareja.

\section{El concubinato en América: en constituciones, códigos civiles y códigos de familia}

- Argentina. Según el art. 2436 de su Código Civil y Comercial del 2014, aprobado por Ley 26994, vigente desde el 1 de agosto de 2015 el llamamiento hereditario legal queda excluido por Matrimonio in extremis, cuando:

La sucesión del cónyuge no tiene lugar si el causante muere dentro de los treinta días de contraído el matrimonio a causa de enfermedad, existente en el momento de la celebración, conocida por el supérstite y desenlace fatal previsible, excepto que el matrimonio sea precedido de una unión convivencial. (Código Civil y Comercial de la República de Argentina, 2014)

- Bolivia. País eminentemente andino, siguiendo las orientaciones de sus sucesivas constituciones de 1945, 1961, 1965 y 1967 se le da total reconocimiento al concubinato.

En efecto su «código de las familias y del proceso familiar» aprobado por Ley 603, del 19 de noviembre de 2014 en su artículo 158 reconoce estas 
uniones bajo la denominación de «unión conyugal libre, o de hecho», reconociéndoles efectos similares al matrimonio y comprendiéndolo entre las formas matrimoniales indígenas como el tantanacu y el servinacu así como las uniones de hecho de los aborígenes y otros en poblaciones campesinas (Ley 603, 2014).

Manda a inscribirlo en el registro civil y le reconoce deberes de asistencia recíproca. Lo mismo encontramos en las legislaciones de Costa Rica, desde 1973, Ecuador, El Salvador, Guatemala, Honduras, Nicaragua, Paraguay, etc.

- Colombia. Mediante Ley 54, de 27 de diciembre de 1990 se pasó a denominarlo «unión marital de hecho», conociéndosele también como «unión libre», exigiéndose que se trate de un proyecto de vida constante, día tras día, por un periodo de al menos dos años.

Esta unión puede ser declarada no solo ante notarios o por sentencia judicial, sino también ante centros de conciliación legalmente constituidos y a través de un acta suscrita por ambos «compañeros».

El art. 1 de esta ley declara:

A partir de la vigencia de la presente ley y para todos los efectos civiles, se denomina Unión Marital de Hecho, la formada entre un hombre y una mujer que, sin estar casados, hacen una comunidad de vida permanente y singular. Igualmente, y para todos los efectos civiles, se denominan compañero y compañera permanente, al hombre y la mujer que forman parte de la unión marital de hecho. (Ley 54, 1990, p. 19)

Esta ley fue materia de una acción de inconstitucionalidad denegada por la Sala Plena de la Corte Constitucional de Casación en el año 2015.

- Costa Rica. Desde 1973 legisló sobre el concubinato mediante el artículo 244 de su Código de Familia en el que establece su reconocimiento judicial, retrotrayendo sus efectos patrimoniales a la fecha en que se inició esa unión. Concede derechos alimentarios entre sus miembros (Ley 5476, 2011). 
- Cuba. Siguiendo su constitución de 1940, el Código de Familia de cuba reconoce estas uniones con la denominación «matrimonio no formalizado», expresando en su artículo 43 lo siguiente: «Los tribunales determinaran los casos en que, por razón de equidad, la unión de personas con edad legal para contraer matrimonio será equiparada por su estabilidad y singularidad al matrimonio civil» (CubaLegalinfo, 2017).

Retrotrae sus efectos a la fecha de inicio de la unión. Produce todos los efectos del matrimonio entre ellos el de darse alimentos.

- Ecuador. El Código Civil del Ecuador, vigente desde el 24 de junio de 2005, en su art. 222 con la sustitución, publicada el 19 de junio de 2015, declara:

La unión estable y monogámico entre dos personas libres de vínculo matrimonial, mayores de edad, que forman un hogar de hecho, genera los mismos derechos y obligaciones que tienen las familias constituidas mediante matrimonio y da origen a una sociedad de bienes.

La unión de hecho podrá formalizarse ante la autoridad competente en cualquier tiempo. (Código Civil Ecuatoriano, 2005)

El artículo 225 del mismo código los autoriza a constituir patrimonio familiar y su artículo 233 también reconoce la presunción pater ist est a favor de los hijos del concubinato.

- El Salvador. Su Código de Familia, promulgado por decreto 677 de 1973 en su artículo 118 reconoce esta institución.

Su correspondiente inscripción debe hacerse en el Registro del Estado Familiar.

- Estados Unidos de Norteamérica. Las uniones no matrimoniales son conocidas como The Common-law marriage, con significación como matrimonio de sui juris, matrimonio informal, matrimonio por hábito, o de hecho; hablándose también de «matrimonio de derecho consuetudinario»; existiendo algunas diferencias entre ciertos estados de 
la unión, así como algunas peculiaridades entre sus diversas tribus nativas (Wikipedia, 2017).

También debemos señalar que en el sistema norteamericano se reconocen los acuerdos entre convivientes, con sujeción a la autonomía de las voluntades concurrentes.

- Honduras. El concubinato está regulado en el Código de Familia. Promulgado por decreto 76-84, publicado en el diario oficial La Gaceta el 16 de agosto de 1984. Permite la separación de bienes, así como la adjudicación a cada concubino de los bienes que le correspondan (Código de Familia, 1984).

- México. Su Código Civil para el Distrito Federal desde 1928, como el del Estado de Hidalgo de 1983, entre otros, reconoce el concubinato, estableciendo su inscripción en los libros de matrimonio del estado familiar, así como la obligación de los concubinos de darse alimentos recíprocamente (Código Civil para el Distrito Federal y Territorios Federales, 1928).

- Nicaragua. En el artículo 72 de su constitución declara:

El matrimonio y la unión de hecho estable están protegidos por el estado; descansan en el acuerdo voluntario del hombre y la mujer y podrán disolverse por mutuo consentimiento o por voluntad de una de las partes. La ley regula esta materia. (Constitución Política de la República de Nicaragua, 2007)

En consecuencia, en Nicaragua el concubinato es una de las formas naturales de la familia. Además, cuentan con un código de familias y mediante Ley 143, de 1992, le reconoce derechos alimentarios.

- Panamá. La Constitución de 1946 y la de 1972 en su artículo 58 reconoce esta institución (Constitución Política de la República de Panamá de 1972, 1996). Su Código de Familia en su artículo 53 también la reconoce, disponiendo que se inscriba en el Registro Civil. Surte todos los efectos del matrimonio civil, reconociéndoles obviamente, derechos alimentarios. 
Entre otros medios probatorios se puede acreditar su existencia con la declaración jurada de dos personas vecinas del lugar donde se ha realizado la unión.

- Paraguay. Su Código Civil de 1985 en su artículo 83 reconoce el concubinato estableciendo en el artículo 86 que después de 10 años podrán solicitar a registro del estado civil, o al juez de paz, la inscripción de la unión, la que se equipara al matrimonio legal. También, presume la paternidad a favor de los hijos de esta unión (Código Civil del Paraguay, 1985).

- Uruguay. Su Ley 18246, del 27 de diciembre de 2007 reconoce el concubinato, disponiendo la ayuda recíproca entre sus miembros.

Igualmente establece que su ordenamiento se hará en vía judicial (Ley 18246, 2007).

- Venezuela. La Constitución de la República Bolivariana de Venezuela, promulgada el 20 de diciembre de 1995 expresa en su artículo 77 lo siguiente:

Se protege el matrimonio entre un hombre y una mujer, fundado en el libre consentimiento y en la igualdad absoluta de los derechos y deberes de los cónyuges. Las uniones estables de hecho entre un hombre y una mujer que cumplan los requisitos establecidos en la ley producirán los mismos efectos que el matrimonio. (Constitución de la República Bolivariana de Venezuela, 1999)

Existe la presunción pater ist est para los hijos nacidos durante el concubinato.

\section{La Ley 30007}

El 17 de Abril de 2013 se publicó en el diario oficial esta ley de 10 artículos, modificando los arts. 326, 724, 816 y 2030 del Código Civil, el inc. 4 del art. 425 y el art. 831 del Código Procesal Civil y los artículos 35, 38, inc. 4 del 39 de la Ley 26662 (1996) a fin de reconocer derechos sucesorios entre los miembros de las «uniones de hecho». 
De esta ley se puede leer que se ha dado únicamente para modificar los citados artículos y solamente para reconocer «derechos sucesorios» a los integrantes de las uniones de hecho, a las que tanto la constitución anterior como la actual eluden denominar por su acepción más usual y conocida de concubinato, Ley 30007 (2013).

Sus dos primeros artículos empiezan declarando que la ley tiene por finalidad otorgar derechos sucesorios entre un varón y una mujer libres de impedimento matrimonial, que conforman una unión de hecho, para cuyo fin es necesario que reúna los requisitos señalados en el artículo 326 del Código Civil (2017) y que se encuentre vigente al fallecimiento de cualquiera de sus miembros.

Es decir, que le impone la condición de ser tal en el momento de la muerte del que deja la herencia, cuando hubiese sido mejor decir «que se encuentre inscrita o reconocida» al fallecimiento de uno de ellos, o que los derechos se pierden para el que unilateralmente pone fin a la unión y no para el abandonado, porque podría entenderse que estos derechos resultarían burlados si al momento del fallecimiento uno había abandonado al otro sin motivo ni razón, a diferencia del matrimonio en el que los derechos hereditarios se extinguen para el cónyuge culpable de la separación.

Seguidamente se precisa que para el reconocimiento de estos derechos sucesorios, la unión debe estar inscrita en el Registro Personal de los Registros Públicos de conformidad con el art. 49 de la Ley 26662, de Competencia Notarial en Asuntos No Contenciosos, (ampliada en esta parte por la Ley 29560), o declarada judicialmente, que son las dos únicas formas establecidas para el reconocimiento de estas uniones.

La primera de ellas, es decir, la reconocida en sede notarial, se realiza a petición de ambos solicitantes cumpliendo con los requisitos de su art. 46 y que luego de la publicación establecida en el art. 13 culmina con la declaración del notario reconociendo la unión y ordenando la remisión de partes al Registro Personal del lugar de domicilio de los solicitantes. 
Por su parte, la declarada judicialmente tiene lugar por demanda del integrante sobreviviente de la unión, si con anterioridad al fallecimiento del causante no se hubiera efectuado la inscripción registral por reconocimiento notarial.

Debemos agregar al respecto que también es posible la demanda de reconocimiento judicial de la unión en vida del conviviente renuente.

\section{Derechos reconocidos a los concubinos}

1. Derecho a constituir una sociedad de bienes:

Por «sociedad de bienes» podemos entender la adquisición y tenencia de bienes por ambos concubinos, que se asimilan al régimen de la sociedad de gananciales en lo que le fuera aplicable, y siempre que haya mantenido no menos de dos años continuos.

Sin embargo, nada impide, ni puede negar a los convivientes optar por anticipado un régimen de separación de patrimonios otorgando la escritura pública correspondiente y su inscripción en el Registro Personal como lo autoriza para los cónyuges el art. 295 del Código Civil (2017).

Igualmente, durante el concubinato podrán sustituir un régimen por otro otorgando la escritura pública respectiva y procediendo a su inscripción en el registro personal. Al respecto debe tenerse en cuenta el principio jurídico de que nadie está prohibido de hacer lo que la ley no impide, y que lo que no está prohibido está autorizado.

2. Derechos sucesorios:

Para darle el necesario sustento jurídico a estos derechos recíprocos, el art. 4 de la ley incorpora al art. 326 del Código Civil, el último párrafo siguiente:

Las uniones de hecho que reúnan las condiciones señaladas en el presente Artículo producen, respecto de sus miembros, derechos y deberes sucesorios, similares a los del matrimonio, por lo que las 
disposiciones contenidas en los Artículos $725^{\circ}, 727^{\circ}, 730^{\circ}$, $731^{\circ}, 732^{\circ}$, $822^{\circ}, 823^{\circ}, 824^{\circ}$ y $825^{\circ}$ del Código Civil se aplican al integrante sobreviviente de la unión de hecho en los términos en que se aplicarían al cónyuge. (Ley 30007, 2013)

Los arts. 725, 727, 730, 731 y 732 corresponden al título de la «legítima» de los herederos forzosos; entendida esta como «la parte de la herencia de la que no puede disponer libremente el testador cuando tiene herederos forzosos», como lo declara el art. 723 de este mismo código.

Es que al concubino, o integrante sobreviviente de la unión de hecho, se le está concediendo la condición de tal, que lo convierte en un heredero obligatorio o necesario de quien fue su conviviente; teniendo en adelante el título de «legitimario», que significa beneficiario de la legítima.

El primer artículo modificado se refiere a la parte de la herencia que el testador puede disponer libremente en legados cuando tiene descendientes, o cónyuge; el segundo a la libre disposición de todos sus bienes cuando no tiene herederos forzosos, y el tercero a declarar que la legitima del cónyuge y del concubino es independiente del derecho que le corresponde por concepto de gananciales. $\mathrm{Al}$ respecto debemos tener presente que conforme al citado art. 326 del Codigo Civil (2017) la sociedad de bienes que se origina en la unión de hecho «se sujeta al régimen de la sociedad de gananciales», en cuanto le fuera aplicable.

Los artículos 731 y 732 se ocupan de los nuevos derechos de habitación y usufructo que el actual Código Civil le ha otorgado al cónyuge para que al fallecimiento de su consorte adquiera automáticamente, es decir, de pleno derecho, los beneficios de habitación y usufructo en forma vitalicia y gratuita sobre la casa habitación en que estuvo constituido el hogar conyugal.

En consecuencia, ahora el conviviente tiene también estos derechos, para cuando, igual que el cónyuge sobreviviente, sus derechos por concepto de legitima y de gananciales no alcanzaran el valor necesario para que le sea adjudicada la referida casa del hogar convivencial. 
Los artículos $823,824,825$ y 826 están referidos, por su orden, a la cuota hereditaria que corresponde al cónyuge; su opción por el usufructo de la tercera parte de la herencia (salvo que hubiera obtenido los derechos de habitación o usufructo); la cuantía de su legítima cuando hereda con padres del causante $\mathrm{u}$ otros ascendientes, $\mathrm{y}$ finalmente a su condición de heredero único cuando no hay descendientes ni ascendientes con derecho a heredar.

El art. 5 de la Ley 30007 (2013) modifica también el artículo 724 del Código Civil para incluir al integrante sobreviviente de la unión de hecho como heredero forzoso conjuntamente con los descendientes y los ascendientes.

Seguidamente se ha modificado el art. 816 del mismo código para incorporar al integrante sobreviviente de la unión de hecho en el tercer orden sucesorio, conjuntamente con el cónyuge; precisando al final que ambos tienen el derecho de concurrir conjuntamente con los descendientes y con los ascendientes; heredando en el primer caso una parte igual que un hijo, y en el segundo igual que cualquier ascendiente.

El art. 7 crea el inciso 10 del art. 2030, del referido código estableciendo que también se inscriben en el Registro Personal de los Registros Públicos «Las uniones de hecho inscritas en vía notarial o reconocidas por vía judicial», con lo cual le otorga a esta inscripción el principio de publicidad, conforme al cual «se presume, sin admitirse prueba en contrario, que toda persona tiene conocimiento del contenido de las inscripciones» y por tanto sus efectos son oponibles erga omnes (Codigo Civil, 2017).

Los artículos 8 y 9 de la Ley 30007 modifican los arts. 425 y 831 del Código Procesal Civil estableciendo nuevos requisitos que deben acompañarse a las demandas, cuando se solicite el inicio de un proceso de sucesión intestada, tales como acompañarse prueba de la calidad de integrante sobreviviente de la unión de hecho, en el primer caso y en el segundo, la constancia de inscripción de la unión de hecho en el Registro Personal.

Finalmente, el art. 10 de la Ley 30007 modifica los arts. 35, 38 y el inc. 4 del art. 39 de la Ley de Competencia Notarial en Asuntos No Contenciosos, 
26662, relacionados a las personas que deben suscribir la solicitud de comprobación de los testamentos cerrado y ológrafo, entre las que se incluye al integrante sobreviviente de la unión de hecho, reconocida conforme a la ley, y también que la solicitud de comprobación la puede solicitar, mediante petición escrita, el integrante sobreviviente de la unión de hecho reconocida también con arreglo a ley.

A continuación, se precisa que la solicitud de protocolización se puede presentar, igualmente, por el integrante sobreviviente de la unión de hecho reconocida de acuerdo a ley, ante el notario del último domicilio del causante.

En cuanto a la modificación final del art. 39 de esta Ley 26662 se agrega, por dicha Ley 30007 (2013), como requisito la solicitud de sucesión intestada, que se deberá acompañar la constancia de inscripción de la unión de hecho en el Registro Personal. Con relación a esta última exigencia, como en el caso de los arts. 8, 9 y 10 de la Ley 30007, los documentos cuya presentación lo requiere, podría asumirse que han devenido en innecesarios, desde que por posterior Decreto Legislativo 1246, expedido el 9 de Octubre de 2016, se dispone que todas las entidades del sector público, entre ellos el Poder Judicial comprendidas en el art. I del Título Preliminar de la Ley 27440, Ley del Procedimiento Administrativo General, de manera gratuita, a través de la interoperabilidad, interconecten, pongan a disposición, permitan el acceso o suministren la información o base de datos actualizados que administren, recaben, sistematicen, creen o posean respecto de los usuarios y administrados, que las demás entidades requieran necesariamente y de acuerdo a ley, para la tramitación de sus procedimientos administrativos y para sus actos de administración interna.

En consecuencia, la presentación de estos instrumentos resultaría innecesaria, bastando con informar el lugar en donde se encuentran.

Finalmente, debemos agregar que solo para el caso que los concubinos dejen de serlo por abandono de uno de ellos, el artículo 326 del código concede al perjudicado una indemnización o recién una pensión 
alimenticia; y para el denominado concubinato impropio autoriza al interesado la acción de enriquecimiento indebido

\section{Nuevos derechos para los concubinos}

1. Adjudicación del hogar convivencial y otros bienes:

Aun cuando la Ley 30007 no modifica el art. 731 del Código Civil (2017), refiriéndose al art. 323 del mismo código (que concede al viudo preferencia para la adjudicación de la casa en la que habita la familia y el establecimiento agrícola, artesanal, industrial o comercial de carácter familiar, con la obligación de reintegrar el exceso de valor, si lo hubiera), le concede similar derecho de habitación sobre el mismo bien, sin expresar que para el citado concubino no es aplicable aquella adjudicación, aquí encontramos un nuevo derecho, que resulta obvio, a favor de aquel, como es la preferencia para que le sea adjudicado en propiedad el expresado predio.

Debemos tener en cuenta que si la Ley 30007 le está concediendo al concubino el derecho a una «sociedad de bienes que se sujeta al régimen de sociedad de gananciales, en cuanto le fuera aplicable», y se le está reconociendo «derechos sucesores similares a los del matrimonio», nada podría impedir que con arreglo al citado art. 323 del Código Civil (2017) cuando esa sociedad de bienes fenece por muerte o declaración de ausencia de uno de sus miembros, el otro tenga preferencia para la adjudicación de la casa en que habita la familia y del establecimiento agrícola, artesanal, industrial o comercial de carácter familiar, con la obligación de reintegrar el exceso del valor, si lo hubiera.

A mayor abundamiento, debemos tener en cuenta que, conforme a la población censada, según el estado civil o conyugal en el 2007, se tiene el siguiente cuadro estadístico, que gráfica el considerable porcentaje de concubinos que, por derecho natural, deberían recibir los beneficios legales. 
Tabla 1

Población censada según el estado civil o conyugal 2007

\begin{tabular}{lll}
\hline Estado Civil o Conyugal & Urbano & Rural \\
\hline Conviviente & $23.3 \%$ & $29.2 \%$ \\
Casado & $28.8 \%$ & $28.0 \%$ \\
\hline
\end{tabular}

Nota: Adaptado de Instituto Nacional de Estadística e Informática (2007). Censos Nacionales 2007, XI de población y VI de vivienda.

2. Beneficiario del patrimonio familiar:

Según el art. 495 del Código Civil pueden ser beneficiarios del patrimonio familiar, los cónyuges y otros familiares.

Sin embargo, constituyendo el concubinato una de las formas de la familia y siendo el concubino integrante de ella, conjuntamente con los hijos del instituyente, no hay razón para que quede excluido de ese beneficio, si precisamente a falta del otro la conducción del hogar y su gobierno serán de su cargo, en mayor medida cuando los hijos fueran menores de edad o incapaces. Por tanto, este beneficio debe serle igualmente reconocido, como lo hace el artículo 225 del Código Civil de Venezuela.

3. Eliminación del principio de prueba escrita:

También debe excluirse de entre las exigencias para probarse la posición constante del estado concubinario el requisito «siempre que exista un principio de prueba escrita», no solo porque el párrafo pertinente del art. 326 del Codigo Civil (2017) empieza expresando que dicha posesión constante de estado puede probarse «con cualquiera de los medios admitidos por la ley procesal», entre los que el art. 238 del Código Civil (2017) trata el "principio de prueba escrita», sino también porque justamente, para ello existen los demás medios probatorios, como la declaración de parte, etc.; medios que la ley de procedimiento en su art. 197 manda valorar en forma conjunta. 
4. Elección y cambio de régimen patrimonial:

Así como los arts. 495 y 296 del Codigo Civil (2017) permiten a los futuros cónyuges optar por el régimen de sociedad de gananciales o por el de separación de patrimonios, e igualmente sustituir uno por otro durante el matrimonio, debe reconocerse a los concubinos, en virtud del principio de la autonomía de la voluntad, a poder elegir por uno o por otro, así como sustituirlo, toda vez que donde hay la misma razón existe el mismo derecho.

No podría alegarse, como no se hace en el matrimonio, que con ello se perjudicaría el derecho de terceros, porque en ambas alternativas la ley manda su previa inscripción en el registro personal para que surta sus efectos.

Igualmente, debe tenerse en cuenta el principio de la autonomía de la voluntad, y también que con arreglo a la Constitución nadie está impedido de hacer lo que la ley no prohibe.

Estos derechos se reconocen expresamente, por ejemplo, en El Salvador, mediante Decreto Legislativo 677 de 1993.

5. Derecho alimentario:

A pesar de la permanencia, vida en común y singularidad, exigidas a los concubinos, mezquinamente no se les reconoce el deber-derecho de darse alimentos y asistirse recíprocamente, postergándose para cuando la unión termine, por «decisión unilateral», es decir, cuando uno abandone al otro para que recién el juez pueda concederle una pensión de alimentos.

Es decir, contrariamente con lo que según el art. 474 del Código Civil (2017) sucede con los cónyuges. Mientras los concubinos estén en la misma casa, no se pueden pedir alimentos, aunque el otro burle su deber, obligando al perjudicado a separase, para irónicamente ser demandado por alimentos a favor del burlador. 
Este derecho se encuentra debidamente reconocido en los códigos de Bolivia, Colombia, Costa Rica, Ecuador, El Salvador, Hondura, Nicaragua, Panamá, entre otros.

6. Declaración expresa de los efectos del inicio del concubinato:

Mientras que en el matrimonio sus efectos se inician en el momento de su celebración, el primer párrafo del art. 326 del Codigo Civil (2017) es confuso con respecto al inicio de los efectos de la unión de hecho. Así, a pesar de que empieza diciendo que la unión de hecho «origina una sociedad de bienes», al final agrega «siempre que dicha unión haya durado por los menos dos años continuos». Es decir, posterga durante esos dos años el nacimiento del concubinato, lo que es obviamente absurdo y contradictorio.

Por su parte la Ley 29560, modificatoria del art. 46 inc. 2 de la Ley 26662, exige para el reconocimiento notarial de la unión de hecho el asentimiento expreso de los solicitantes que conviven no menos de dos años de manera continua (Ministerio de Justicia, 1979).

Todo ello lleva a concluir por algunos, erróneamente, que los efectos del concubinato nacen después de los dos años de la unión y que, por ejemplo, los bienes adquiridos en común antes de los dos años pertenecen a cuyo nombre se han puesto y no a la sociedad de bienes y por tanto no se les puede aplicar las reglas de la sociedad de gananciales.

Ante ello, y a pesar de que la resolución que reconozca o declare la unión no es de naturaleza constitutiva, sino meramente declarativa, es preciso que por norma expresa se establezca, por justicia y razón, que los efectos de esta unión se retrotraen al día de su inicio, y no dejar un periodo de desamparo para la parte desfavorecida.

7. Las acciones petitoria y reivindicatoria de herencia:

Siendo el concubino heredero forzoso debe establecerse, expresamente, que está autorizado a ejercer las acciones petitoria y reivindicatoria de herencia, y que puede ejercer con la primera, acumulativamente, las 
acciones de reconocimiento judicial de la unión de hecho que autoriza el segundo párrafo del art. 3 de la Ley 30007, y la de ser declarado heredero si considera que sus derechos han sido pretéritos por una declaración anterior.

Esto guardaría concordancia con lo establecido en el art. 664 del Codigo Civil (2017) para los herederos que buscan el reconocimiento de sus derechos.

8. El concubinato putativo:

El matrimonio putativo es un efecto de la sentencia de nulidad del matrimonio, que favorece a determinadas personas.

Así como en el matrimonio los arts. 284 y 827 del Codigo Civil (2017) reconocen efectos civiles y sucesorios, respectivamente, a favor de quienes lo contrajeron de buena fe, también debe reconocerse tales derechos en el concubinato para los que lo han conformado de buena fe, o para aquel que ha procedido de esa manera, aun cuando su reconocimiento sea declarado nulo posteriormente.

En efecto en el art. 284 del mismo Codigo Civil (2017) se establece:

El matrimonio invalidado produce efectos civiles respecto de los cónyuges e hijos si se contrajo de buena fe, como si fuese un matrimonio válido disuelto por divorcio. Si hubo mala fe en uno de los cónyuges, el matrimonio no produce efectos en su favor, pero sí respecto del otro y de los hijos. El error de derecho no perjudica la buena fe.

En su art. 827 se declara:

La nulidad del matrimonio por haber sido celebrado con persona que estaba impedida de contraerlo no afecta los derechos sucesorios del cónyuge que lo contrajo de buena fe, salvo que el primer cónyuge sobreviva al causante. 
En consecuencia, no hay razón para no conceder al concubino de buena fe los beneficios que le corresponden en caso de una unión válida cuando cumple las condiciones de los dos artículos citados, aun cuando se haya declarado su invalidez, como lo hace el sistema legal de Honduras mediante el Decreto Legislativo 76, de 1984.

9. Separación judicial en la unión de hecho:

Por las mismas causas que procede la separación de cuerpos en el matrimonio el juez podría declarar la cesación del concubinato aplicando las causales pertinentes del art. 333 del Código Civil, puesto que podría darse culpa en uno de sus miembros, como suele suceder entre cónyuges.

También, debería autorizarse la suspensión de la cohabitación prevista en el art. 289 del mismo código cuando su cumplimiento ponga en grave peligro la vida, la salud o el honor de cualquiera de ellos, o la actividad económica de la que depende el sostenimiento familia.

10.Declaración e inscripción del concubinato y su terminación en el Registro Civil o en un centro de conciliación autorizado:

Si el concubinato no solo es una de las formas de la familia, sino también una institución similar al matrimonio, para alcanzar finalidades y cumplir deberes semejantes a él, debe reconocérsele e inscribírsele en el Registro Civil de las Municipalidades, con conocimiento del Registro Nacional de Identificación y Estado Civil (RENIEC), y no en el Registro Personal de los Registros Públicos. De igual forma, en el Registro Civil también debe inscribirse su terminación.

En muchas legislaciones, como Bolivia, Cuba, México, Paraguay, etc., donde se le denomina «libros de matrimonio del estado familiar», Paraguay, ello es así, por lo que no hay razones para haber remitido su declaración a los notarios, y su posterior inscripción en otra entidad, como es el Registro Personal, con la tramitación, dilación y considerables costos que ellos irrogan. 
De otro lado, si los municipios están facultados para celebrar matrimonios, e inclusive, ahora, para declarar divorcios, e inscribirlos, no existe explicación válida para no darles la misma intervención en los concubinatos.

En consecuencia, considero que la declaración de las uniones de hecho debe realizarse e inscribirse esta en el Registro Civil, con registro en el RENIEC para los fines que la ley establece.

A mayor abundamiento, existen legislaciones que autorizan su reconocimiento ante centros de conciliación autorizados.

Además, debe tenerse en cuenta, que el art. 262 de nuestro Codigo Civil (2017) reconoce, inclusive, la celebración de los matrimonios en las «comunidades campesinas y nativas ante un comité especial constituido por la autoridad educativa e integrado por los dos directivos de mayor jerarquía de la comunidad».

En consecuencia, nada justifica el encarecimiento de esta declaración e inscripción, remitiéndola a la competencia de los notarios y del Registro Personal de los Registros Públicos, cuando conforme un cuadro estadístico mostrado anteriormente la mayoría de las uniones de hecho se dan el ámbito rural, donde no hay notarías ni Registro Personal, pero sí municipalidades delegadas.

11.Establecimiento de causales de nulidad:

Similar al matrimonio debe precisarse causales para la nulidad de las declaraciones de las uniones de hecho, puesto que pueden haberse obtenido con infracción de prohibiciones, o con omisión de requisitos expresos exigidos por la ley, así como con fines ilícitos, o por personas incapaces, etc., que las tornan irremediable nulas, a pesar de que ya se encuentran inscritas en los Registros Públicos, con todas las consecuencias y efectos que de ellas se derivan, tanto para particulares como para el propio Estado, afectando un matrimonio o una unión de hecho anteriores. 
Obviamente que tal nulidad será declarada en sede judicial, mediante la correspondiente sentencia.

12.Presunción legal de paternidad:

Como para la existencia de la unión de hecho o concubinato se exigen los requisitos de publicidad o notoriedad, de estabilidad y exclusividad es justo que para estas uniones se reconozca también la presunción de paternidad en la forma que lo hacen otros códigos civiles como el de Ecuador, Paraguay, etc. y el art. 361 de nuestro Codigo Civil (2017) para el caso del matrimonio y en consecuencia que el hijo tenga por padre al concubino cuando nace durante la unión de hecho o dentro de los trescientos días siguientes a su terminación.

La presunción pater ist est podrá ser desvirtuada mediante la acción de negación de la paternidad en los casos del art. 363, que fueran aplicables.

Además, ya el art. 402 inc. 3 del mismo Código Civil establece la posibilidad de declarar la paternidad extramatrimonial cuando el presunto padre hubiera vivido en concubinato con la madre en la época de la concepción.

\section{Parentesco por afinidad:}

El parentesco por afinidad es el que resulta del matrimonio entre cada uno de los cónyuges con los parientes consanguíneos del otro. Cada cónyuge se halla en igual línea y grado de parentesco por afinidad que el otro por consanguinidad», lo que se lee en el art. 237 del Código Civil.

Agrega el mismo art. 237 que la afinidad en línea recta no termina por la disolución del matrimonio que la origina y que en el segundo grado de la línea colateral (cuñados) la afinidad subsiste también en caso de divorcio mientras viva el excónyuge.

Por su parte el art. 242 del propio código, a modo de reiteración, establece que no pueden contraer matrimonio entre sí: los afines en línea recta y los afines en el segundo grado de la línea colateral (cuñados) cuando el 
matrimonio que originó la afinidad acabó por divorcio y el excónyuge vive.

En consecuencia, siguiendo la misma orientación debe establecerse el parentesco por afinidad en las uniones de hecho a efecto de impedir una nueva unión tanto entre un exconcubino con los parientes en línea recta del otro (padres, abuelos, hijos, etc.) así como también con sus hermanos estando vivo el otro, toda vez que para que se constituya el concubinato sus integrantes deben estar libres de impedimento matrimonial.

\section{Referencias}

Código Civil (1852). Publicado por Ley del 23 de diciembre de 1851. Recuperado de http://blog.pucp.edu.pe/blog/ conciliacion/wp-content/uploads/sites/76/2015/06/Codigo_civil_de_1852.pdf

Código Civil. (2017). Editorial Jurista Editores. Autor institucional.

Código Civil Ecuatoriano. (2005). Recuperado de http://www.abogadosdecuador.com/codigo-civil.htm

Código Civil de 1936. (1971). Lima: Amauta.

Código Civil del Paraguay. (1985). Ley 1183/85. Recuperado de https://www.oas.org/dil/esp/Codigo_Civil_Paraguay.pdf

Código de Familia (1984). Recuperado de http://www.acnur.org/t3/fileadmin/Documentos/BDL/2016/10420.pdf

Código Civil y Comercial de la República de Argentina. (2014). Recuperado de http://www.wipo.int/wipolex/es/ text.jsp?file_id=377059

Código Civil para el Distrito Federal y Territorios Federales. (1928). Recuperado de http://www.diputados.gob.mx/ LeyesBiblio/ref/ccf/CCF_orig_26may28_ima.pdf

Constitución de la República Bolivariana de Venezuela. (1999). Recuperado de http://www.oas.org/dil/esp/ constitucion_venezuela.pdf

Constitución Política de la República de Nicaragua. (2007). Recuperado de http://www.wipo.int/edocs/lexdocs/laws/ es/ni/ni033es.pdf

Constitución Política de la República de Panama de 1972. (1996). Recuperado de http://www.meduca.gob.pa/sites/ defaultfiles/editor/48/constitucion1972re.pdf

Constitución Política del Perú de 1979 (1979). Recuperado de http://www4.congreso.gob.pe/comisiones/1999/ simplificacion/ const/1979.htm

Constitución Política del Perú de 1993. (2008). Ministerio de Justicia (7ª ed.). Lima: Colección Jurídica.

CubaLegalinfo. (2017). Del Matrimonio No Formalizado - Texto aclaratorio. Recuperado de http://www.cubalegalinfo.com/ codigo-familia-matrimonio-no-formalizado

Fernandez de León, G. (1962). Diccionario de Derecho Romano. Buenos Aires: S.E.A.

Instituto Nacional de Estadística e Informática. (2007). Censos Nacionales 2007, XI de población y VI de vivienda. Recuperado de https://http://censos.inei.gob.pe/cpv2007/tabulados/ 
Ley 26662. (1996). Ley de Competencia Notarial en Asuntos No Contenciosos. Recuperado de https:// www.minjus.gob.pe/wp-content/uploads/2014/03/Ley26662.pdf

Ley 18246. (2007). Ley de unión concubinaria. Recuperado de https://www.impo.com.uy/bases/leyes/18246-2007

Ley 5476. (2011). Recuperado de https://www.oas.org/dil/esp/Codigo_de_Familia_Costa_Rica.pdf.

Ley 30007. (2013). Recuperado de http://busquedas.elperuano.com.pe/normaslegales/ley-que-modifica-los-articulos326- 724-816-y-2030-del-codi-ley-n-30007-925847-1/

Ministerio de Justicia. (1979). Constitución Política del Perú.

Peinado, F. (1993). Código de Hammurabi. Madrid: Nacional.

Rojas, L. (2005). Para una historia del Matrimonio Occidental. La sociedad Romano Germánica. Siglos VI-VI. Theoria, 14(1), 47-57. Recuperado de http://www.ubiobio.cl/theoria/v/v14/a5.pdf

Sopena, R. (1963). Enciclopedia Universal Sopena (Tomo 3). Barcelona: Sopena.

Wikipedia. (2017). Common-law marriage. Recuperado de https:/les.wikipedia.org/wiki/Common-law_marriage 